\title{
An acute myocardial infarction due to Brucella prosthetic valve endocarditis starting shortly after the onset of non-specific symptoms
}

\author{
Semra Aktürk, Hakan Kaya, Erdal Aktürk
}

Adıyaman Üniversty, Adıyaman, Turkey

\section{Correspondence to} Dr Semra Aktürk, semrakayakturk@hotmail. com.tr

Accepted 14 January 2015

\section{DESCRIPTION}

Brucellosis most commonly causes fever, drenching night sweats and musculoskeletal symptoms, but in 1-2\% of cases, it becomes complicated with endocarditis, which accounts for most of the mortality. ${ }^{12}$ Brucella prosthetic valve endocarditis (PVE) is a

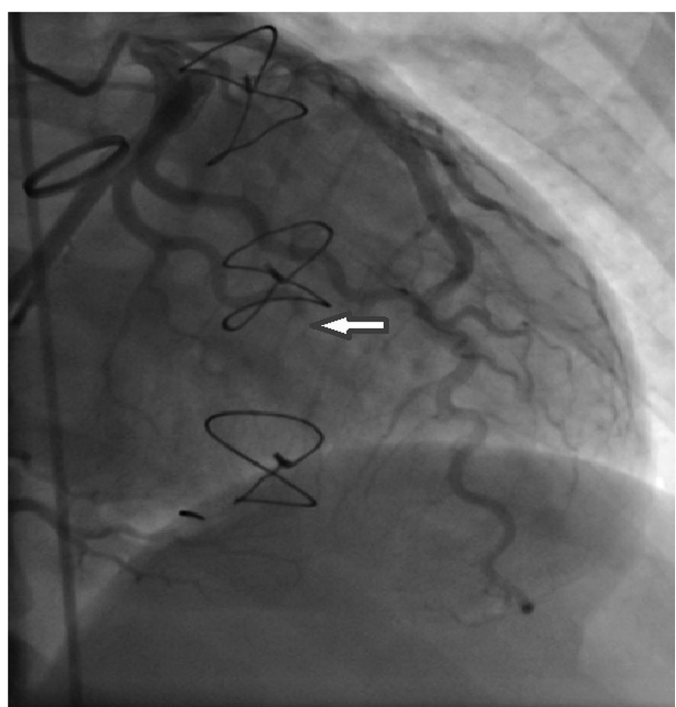

Figure 1 Arrow shows complete occlusion circumflex coronary artery. rare entity, and available data are limited to case reports or small case series.

We present a case report in which a 36-year-old man was admitted to the hospital with new-onset generalised muscle and back pain. Rheumatology clinic hospitalised the patient for further evaluation. The patient had undergone a mechanical heart valve replacement for aortic position 4 years ago. A cardiac evaluation 1 week earlier was unremarkable with an international normalised ratio of 3.1 and a normal functioning bileaflet aortic valve prosthesis on transthoracic echocardiography (TTE). The patient reported severe chest pain after $8 \mathrm{~h}$ following hospitalisation. An ECG showed ST-segment elevations in inferior leads, which was consisted with an acute inferior myocardial infarction. An emergency coronary angiography was then performed, which showed a complete occlusion in the distal circumflex $(\mathrm{Cx})$ coronary artery (figure 1). Percutaneous transluminal coronary angioplasty with stenting restored Thrombolysis in Myocardial Infarction- 3 coronary flow in the $\mathrm{Cx}$ artery. In the meantime, a normally functioning bileaflet aortic valve prosthesis was noted on fluoroscopy (figure 2A, B). TTE and transoesophageal echocardiography revealed a vegetation on the aortic valve prosthesis (figure 3A, B). Empirical antibiotherapy was begun for PVE after obtaining blood cultures, which eventually yielded Brucella melitensis, thus further confirming Brucella PVE.
To cite: Aktürk S, Kaya $\mathrm{H}$ Aktürk E. BMJ Case Rep Published online: [please include Day Month Year] doi:10.1136/bcr-2014209001
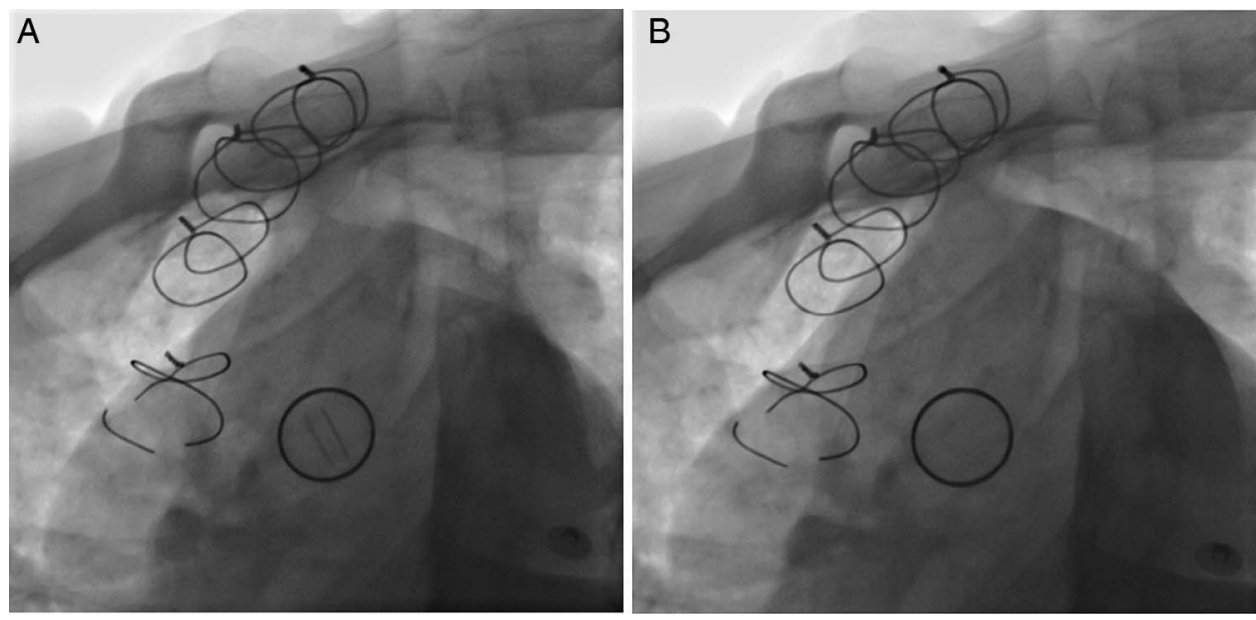

Figure 2 A and B fluoroscopy of normally functioning bileaflet aortic valve prosthesis. 

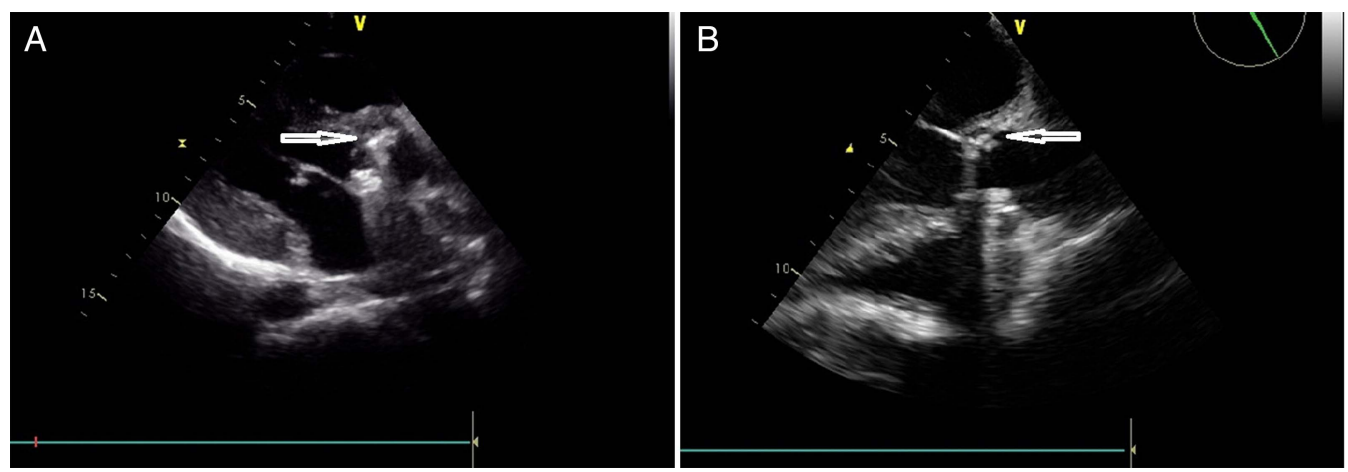

Figure 3 (A) Transthoracic echocardiography (B) transesophageal echocardiogram, arrows showing vegetation on aortic valve prosthesis.

\section{Learning points}

- Brucella endocarditis is a rare clinical entity with a high mortality rate.

- Brucella endocarditis should be taken into account in the differential diagnosis in endemic regions for Brucella and in those patients who are at high risk for Brucella endocarditis.

- Our case report was notable for its different clinical presentation, acute myocardial infarction, starting shortly after the onset of non-specific symptoms.
Contributors SA was involved in the article writing, data collection, language assessment, analysis of radiological images, making assessments. HK was involved in the data collection, analysis of radiological images, making assessments. EA was involved in the article writing, language assessment, analysis of radiological images.

\section{Competing interests None.}

Patient consent Obtained.

Provenance and peer review Not commissioned; externally peer reviewed.

\section{REFERENCES}

1 Pappas G, Akritidis N, Bosilkovski M, et al. Brucellosis. N Engl J Med 2005;352:2325-36.

2 Reguera JM, Alarcon A, Miralles F, et al. Brucella endocarditis: clinical, diagnostic, and therapeutic approach. Eur J Clin Microbiol Infect Dis 2003;22:647-50.

Copyright 2015 BMJ Publishing Group. All rights reserved. For permission to reuse any of this content visit http://group.bmj.com/group/rights-licensing/permissions.

BMJ Case Report Fellows may re-use this article for personal use and teaching without any further permission.

Become a Fellow of BMJ Case Reports today and you can:

- Submit as many cases as you like

- Enjoy fast sympathetic peer review and rapid publication of accepted articles

- Access all the published articles

- Re-use any of the published material for personal use and teaching without further permission

For information on Institutional Fellowships contact consortiasales@bmjgroup.com

Visit casereports.bmj.com for more articles like this and to become a Fellow 